\title{
17. Grandparent status and multigenerational relationships
}

\author{
Jan Skopek
}

\section{INTRODUCTION}

In the wake of the second demographic transition, changes in marriage and fertility behaviour, in conjunction with the mortality revolution, have profoundly affected how family is experienced in contemporary western societies (Lesthaeghe 2010). One aspect of changing family life that has received increasing attention from family scholars is the multigenerationalisation of the modern family and its consequences. According to Bengtson's (2001) widely cited theory on the rising importance of multigenerational bonds, declining fertility and soaring longevity caused family structures to morph from being 'pyramids' to being 'beanpoles' in which multiple generations in a family spent more of their years of life together than ever before. In response to those changes, family sociologists have produced a growing body of research on the meaning, functioning, and consequences of extended kinship and multigenerational family relations. In this chapter, I focus on one of the most common, and, thus, one of the most significant multigenerational bonds: that of grandparents and their grandchildren.

Research on grandparenthood has been greatly expanding in recent decades. One reason why this topic is attracting increasing attention is that becoming a grandparent marks a key transition in people's lives that reconfigures family relations and the associated roles in middle and later life stages. Thus, family research has occasionally referred to the transition to grandparenthood as a 'counter-transition' that marks a life change that is not directly self-initiated, but is instead caused by the transition to parenthood for the younger generation (Hagestad and Lang 1986). Nonetheless, the arrival of the first grandchild sets in motion a 'transition domino' that creates new role expectations as people move up in the generational structure of their family lineage (Hagestad and Burton 1986). For people who are ageing, progressing in the generational hierarchy of the family can be a strain, but also a joy. Indeed, a number of studies have shown that taking on the grandparent role can be a source of well-being, life satisfaction, identity, social support, and meaning for older individuals (Lye 1996; Silverstein and Long 1998). For example, Arpino et al. (2018) found that being a grandparent in Europe is associated with increased subjective well-being, and that active grandparenting - i.e., spending time with grandchildren and looking after them - is the primary source of this positive association. Other research has also demonstrated that for grandparents, spending time with their grandchildren can have positive effects on their physical and mental health, and on their cognitive functioning (Arpino and Bordone 2014; Burn and Szoeke 2015; Condon et al. 2018; Di Gessa et al. 2016; Szinovacz and Davey 2005). However, as caring for grandchildren may also involve stress, grandparenting responsibilities can be detrimental to older people's health outcomes (Minkler and Fuller-Thomson 1999), particularly when the care demands are high (e.g., in skipped-generation households in which the grandparents take on the primary care obligations), and when the grandparents have competing roles (Hughes et al. 2007; Musil et 
al. 2011). Furthermore, when older couples become grandparents, traditional gender roles and a gendered division of labour may be reactivated (Hank and Buber 2009; Leopold and Skopek 2014).

The childcare and family support provided by grandparents can be a crucial pillar of family solidarity and functioning. In contexts in which levels of female labour force participation are high and demands for non-parental childcare are rising, grandparents represent an important source of care assistance that can stabilise the economic status of the middle generations by allowing young parents, and particularly mothers, to work and earn income (Luo et al. 2012; Presser 1989). The amounts of time grandmothers and grandfathers spend looking after their grandchildren are substantial, but vary considerably across welfare states, which underlines the relevance of public childcare policies (Hank and Buber 2009; Leopold and Skopek 2014). Gender is a dominant factor, as grandmothers provide the majority of the childcare support (Leopold and Skopek 2014; Spitze and Ward 1998), which can have consequences for the labour supply of older female workers (Bavel and Winter 2013). Grandparents, and particularly grandmothers, may also be 'rescuers' in situations of family crisis such as divorce or parental loss (Cherlin and Furstenberg 1986; Jappens and Bavel 2019; Thompson 1999).

For young children, grandparents may be significant agents of socialisation and providers of resources that can enhance their social mobility and improve their long-term life outcomes. Given the important role grandparents can play in their grandchildren's lives, a number of studies have examined the operation of 'multigenerational' effects on life course outcomes. For example, while taking the middle generation into account, several studies have found that grandparental resources and socio-economic status were associated with favourable grandchild outcomes in a variety of domains, such as cognitive development, physical health, and occupational attainment (Chan and Boliver 2013; Hertel and Groh-Samberg 2014; Modin et al. 2012; Modin and Fritzell 2009). Other studies have found that grandparent effects occur only in co-resident multigenerational households (Zeng and Xie 2014), are concentrated among lower-class children (Wightman and Danziger 2014), or cannot be detected (Bol and Kalmijn 2016). A common shortcoming of the literature on multigenerational influences - and one possible explanation for the mixed evidence on grandparent effects - is that most of these studies did not consider multigenerational exposure; i.e., the actual shared lifetime of grandparents and grandchildren, which multigenerational effects are likely contingent upon (Song and Mare 2019).

Given the growing body of research on grandparents and grandparenthood (Hank et al. 2018), it is surprising how little is known about the changing demographic fabric of the grandparent-grandchild relationship. For example, at what point in their lives do people become grandparents? How long is the grandparent phase expected to last in peoples' lives? To what extent has the number of multigenerational family ties changed? How much of their lifetime do grandchildren spend with their grandparents? Has the time grandparents and their grandchildren spend together been increasing, as many family scholars believe? What is the role of social class and gender in shaping the demographics of multigenerational relationships? These questions are complex, but addressing them is crucial given that the meaning, significance, and performance of multigenerational family roles are contingent upon the demographic context in which they play out. Indeed, tracing empirically the changing demographic and life course contexts of multigenerational relations turns out to be a challenging and elusive area of research. The obstacles to the empirical study of those questions include a dearth of good data, as well as conceptual and methodological challenges. Hence, up to today, empirical 
answers to the questions above continue to be scattered and incomplete. As I will show in this chapter, this is especially the case for European societies, as the empirical evidence on these issues that is available mainly applies to North America.

While focusing on the grandparent-grandchild type of multigenerational relationship, my aim in this chapter is twofold. First, I will review the rather scarce available evidence on the demography of grandparenthood and multigenerational families. This review will also discuss some methodological challenges researchers face when studying grandparenthood and multigenerational relations based on contemporary data. Second, using demographic kinship models, I will analyse multigenerational indicators in order to explore the question of how the demographic context of grandparenthood and multigenerational relations in Europe might have changed from the middle of the twentieth century up to today.

\section{RESEARCH ON THE DEMOGRAPHY OF GRANDPARENTHOOD}

\subsection{Age at Entry into Grandparenthood}

In the field of family research, interest in the demography of grandparenthood was sparked as early as in the 1980s, when life course scholarship became increasingly concerned with investigating the life-style consequences of prolonging longevity (Treas and Bengtson 1982). Although research on the grandparenthood role, as well as on the meaning and significance of multigenerational family interactions, was thriving at that time (Szinovacz 1998a), the lack of empirical knowledge on the changing demographic and life course contexts of grandparenthood was recognised. This issue was raised alongside a general critique that family scholarship had been turning a blind eye to the effects of demographic change on families. For example, as Uhlenberg (1980, p. 313) expressed it, the 'impact of mortality change upon family structure, although sometimes mentioned, has been seriously neglected in studies of family history'. In a series of works, Hagestad and colleagues discussed how demographic change might have affected grandparenthood as a life course passage (Hagestad 1988; Hagestad and Burton 1986; Hagestad and Lang 1986), observing that '[p]opular depictions of grandparents [may] often reflect myths that are out of step with demographic realities' (Hagestad and Lang 1986, p. 117). Indeed, based on evidence for the United States (US) that life expectancy is rising and childlessness rates are declining, Hagestad and her colleagues predicted that the grandparenthood role will become increasingly prevalent, particularly among women, and will last over longer stretches of people's lifespans than ever before.

Moreover, older demographic studies suggested that declining mortality had a profound impact on American family structure, particularly with respect to the 'supply' of living grandparents for children (Uhlenberg 1980; 1996). For example, in the US, the share of children who could expect to have four living grandparents when they reached age 10 increased from around 6.4 per cent in 1900 to almost 40 per cent by the end of the twentieth century (Uhlenberg 1996). Similarly, the proportion of US adults who could expect to still have living grandparents when they reached age 30 rose from around one-fifth in 1900 to three-quarters in the 2000s. Astoundingly, in the 2000s it was 'more likely that 20 -year-olds alive now have a grandmother still living (91 per cent) than that 20-year-olds alive in 1900 had a mother still living (83 per cent)' (Uhlenberg 1996, p. 685). Those simple figures suggest that the mortality 
'revolution' has contributed to a steady rise in multigenerational co-survivorship over extended periods of people's lives. While the supply of living grandparents for children has risen, the 'supply' of grandchildren for older people has fallen as a result of concurrent declines in fertility levels. For example, according to an analysis performed by Uhlenberg and Kirby (1998), among US women aged 60 to 64, the mean number of grandchildren had decreased from about 12 in 1900 to about six in 1980. All of these estimates were generated based on demographic 'period data', i.e., researchers used period life table and period fertility data to provide a 'synthetic picture' of the changes in the demographic context of the grandparent-grandchild relationship. Nonetheless, these findings suggest that multigenerational family structures, and grandparenthood in particular, have undergone substantial changes over the past century.

Other studies have employed survey data to study the demography of grandparenthood, and especially the age at which the transition to grandparenthood typically occurs. Szinovacz's (1998b) analysis based on data from the National Survey of Families in Households (US) collected in the early 1990s is one of the pioneering works on this topic. Her findings suggest that grandparenthood was a nearly universal and typical mid-life experience, and that many individuals had surviving grandparents up to their late 20 s. However, the evidence that families spanning four generations (relationships between great-grandparents and great-grandchildren) were becoming increasingly common, which is one of the predictions of the popular 'beanpole family' theory, was limited. Notably, Szinovacz (1998b) provided for the first time results on the timing of the transition to grandparenthood in the US, thereby addressing the putatively simple, but previously unexplored question of at what point in the life course people actually become grandparents. The availability of the National Survey of Families in Households data made it possible to investigate this question, because the questionnaire included an item on the age of the oldest grandchildren, which provides a viable marker for reconstructing the age at which an individual became a grandparent for the first time. Based on these data, she estimated that the mean age at first-time grandparenthood was 46 for women and 49 for men. Thus, her findings characterised the passage into grandparenthood as a mid-life event that often occurs long before retirement. Subsequent analyses estimated that the mean age at which people transitioned to grandparenthood was 54 for women and 57 for men in Canada (Kemp 2003), and was 52 for women and 55 for men in the Netherlands (Dykstra and Komter 2006). Methodologically, however, many of these earlier survey estimates were problematic, as they were prone to several sorts of bias. Perhaps most importantly, simple mean estimates calculated only for those who were grandparents at the time of the interview can be seen as naïve underestimations of the age at grandparenthood, because they suffered from a right-censoring bias (i.e., they ignored all of the people who may have experienced the transition to grandparenthood after the survey interview). Furthermore, as the survey data only included information on survivors, a left-censoring bias might have occurred if the levels and the timing of fertility (of individuals and their offspring) correlated with mortality risks. In addition, due to data limitations, Kemp's estimates for the timing of grandparenthood had to draw on responses from the middle generation (i.e., the parent's age at the birth of the respondent's first child). This may have caused a systematic upward bias in estimates of the age at grandparenthood, because the childbirths of the respondents' siblings (which may have occurred earlier) were not considered.

Up to now, the most comprehensive analysis of the transition to grandparenthood has been provided by Leopold and Skopek in a recent series of studies that assessed (a) international variation in the transition to grandparenthood, and where the transition to grandparenthood 
fits in the sequence of other transitions that typically occur in mid- and later life (Leopold and Skopek 2015b); (b) cohort changes in the transition to grandparenthood (Leopold and Skopek 2015a); and (c) how educational attainment affects the prevalence and the timing of grandparenthood (Skopek and Leopold 2017). In contrast to previous survey data studies that were largely cross-sectional and focused on North America or single countries, Leopold and Skopek's analyses provided for the first time results on the demography of grandparenthood in various European countries. Moreover, in order to reduce bias related to survey estimates, the authors proposed specific sample designs to ensure that the analysis included only those individuals who were 'at risk' of experiencing grandparenthood, and used survival time methods, which tend to be more reliable for handling right-censored transition data.

Based on data from Leopold and Skopek (2015b), Figure 17.1 displays the results of an analysis on the timing of grandparenthood in various European countries and the US by plotting the quartile ages of the estimated distribution of the ages at the transition to grandparenthood. The figure shows that among people who ever had children, the median age at the transition to grandparenthood was 51 for women and around 54 for men; and that by age 57 for women and by age 61 for men, three-quarters of people who had ever had children had become grandparents. The analysis also found considerable cross-national heterogeneity in the distribution of the ages at which individuals experienced the transition to grandparenthood. For example, the results showed that in Ukraine (as in other Eastern European countries), mothers typically became grandmothers in their mid-40s, whereas in West Germany and Switzerland, mothers became grandmothers 10 or more years later, when they were in their mid- or late 50s. Furthermore, the findings put the previously researched case of the US in a cross-national context by showing that in Eastern European countries, the median age at the transition to grandparenthood is roughly as low as it is in the US. Thus, these comparative findings demonstrate that results based on data from North America cannot be easily generalised to the more heterogeneous national contexts of Europe. Leopold and Skopek (2015b) also provided evidence of cross-national heterogeneity in the life course contexts in which the transition to grandparenthood is experienced by men and women. For example, they found that in Eastern Europe, many people who became grandparents were still active parents of minor children, were still co-residing with their own children, and/or were in the mid-life stages of their work careers. Moreover, they showed many of the women who became grandmothers still had living mothers. Yet they also found that in western continental Europe, grandparenthood generally occurred in an entirely different life course context. In these countries, most people became grandparents at a time in life when their own parents were deceased, their children were grown up and had left home, and they were preparing to retire. Taken together, these findings imply that how the grandparenthood role is typically experienced and fulfilled might differ considerably across countries. Although we focus here on gender and country differences, it should be noted that there is also considerable social heterogeneity in grandparenthood outcomes (Arpino et al. 2017; Skopek and Leopold 2017).

Finally, at the current time, there is almost no representative survey research that has addressed the question of how the transition to grandparenthood has been changing over time. An exception is Leopold and Skopek (2015a), who analysed German cohorts born from 1929 to 1958 using data from the German Ageing Survey. Based on the methodology of Leopold and Skopek (2015b), the study estimated that there was an approximate three-month delay per cohort year in the age at first-time grandparenthood. Those delays implied that the typical age range at the transition to grandmotherhood went from late 40 s to mid-50s among women in 
East Germany, and from mid-50s to early 60s among women in West Germany. Drawing on a period rather than cohort approach, Margolis (2016) found similar trends for Canada.
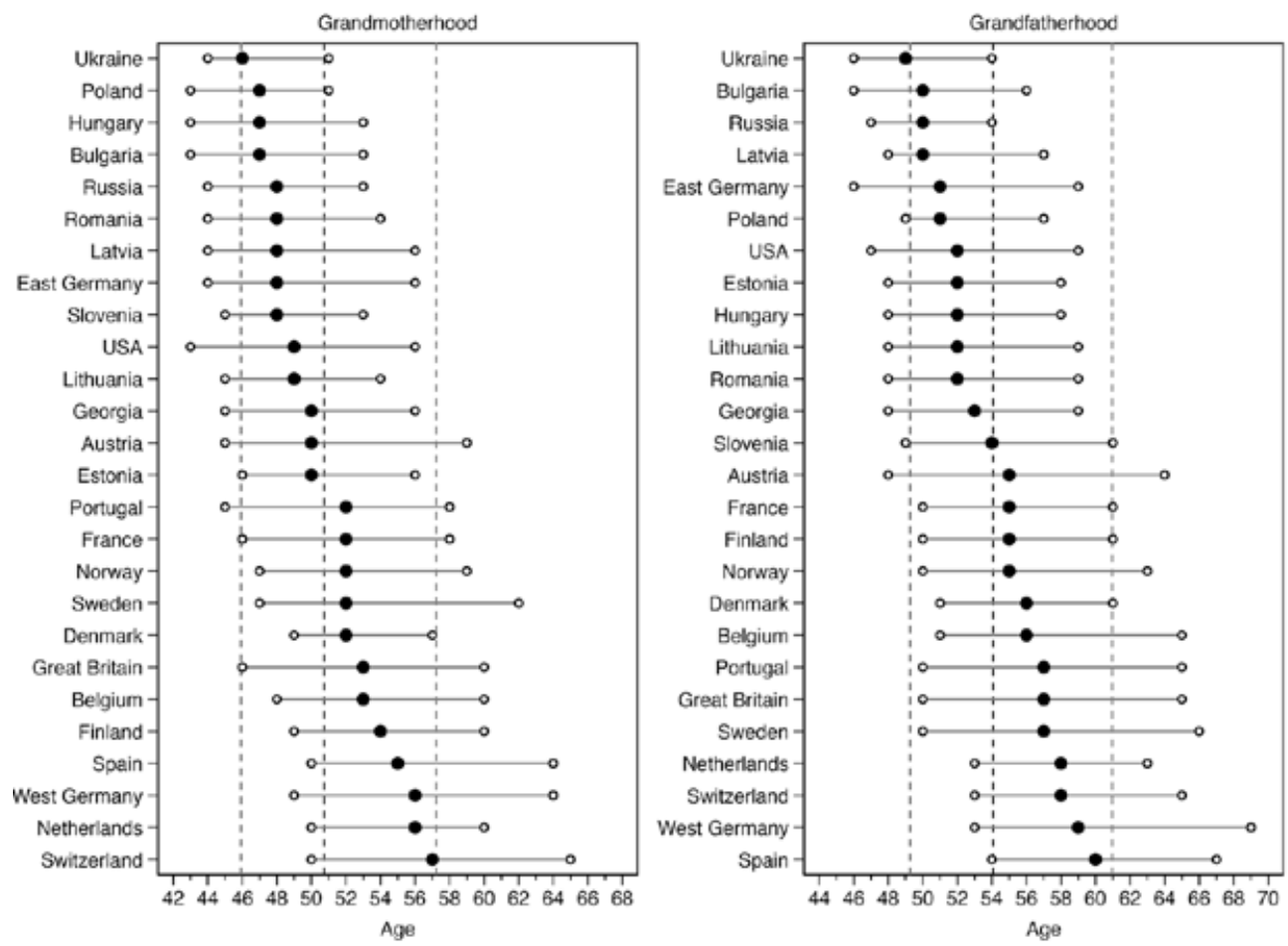

Note: Quartile ages at the transition to grandparenthood. From left to right: 25 per cent quartile (early grandparenthood), 50 per cent quartile or median age (on-time grandparenthood), 75 per cent quartile (late grandparenthood). Dashed vertical lines show average quartile ages ( $N=26$ countries) accordingly. Cohorts born in the 1930s and 1940s.

Source: Data based on Leopold and Skopek (2015b).

Figure 17.1 Age at the transition to grandparenthood for European countries and the United States

\subsection{Duration of Grandparenthood}

Family sociologists have often hypothesised that the increasing longevity of parents, grandparents, and great-grandparents has enlarged multigenerational co-survivorship, and has thus increased the number of years generations spend together (Bengtson 2001). However, the extent to which we actually observe a prolongation of the grandparenthood phase is an empirical question, as longevity gains might be offset by concurrent (multigenerational) delays in fertility that have, in turn, led to delays in the transition to grandparenthood. Nonetheless, the validity of Bengtson's hypothesis has rarely been empirically studied (Herlofson and Hagestad 2011). In particular, the length of multigenerational relationships and exposures, and the numbers of years between multiple generations, are among the least explored issues of multigenerational demography (Margolis and Verdery 2019). 
Taking the difference between life expectancy at age 60 and the median age at the transition to grandparenthood, Leopold and Skopek (2015b) provided a crude but simple measure for estimating the expected length of grandparenthood for their study population (birth cohorts of the 1930s and 1940s). In addition to observing gender differences - i.e., that grandmotherhood generally lasts longer than grandfatherhood, because women are often younger when they first enter parenthood and have higher life expectancy than men - they found substantial cross-national variation in the length of the grandparent phase, with the longest phases found for East Germany ( 36 years for women and 29 years for men) and the US (34 years for women and 28 years for men), and the shortest phases found for West Germany, the Netherlands, and Switzerland (about 28 years for women, and 21-23 years for men). Moreover, they showed that later grandparenthood correlated substantially with higher life expectancy at the country level ( 0.72 for women and 0.79 for men), which suggests that higher life expectancy does not necessarily imply that more years of life are shared across multiple generations. However, as these findings were limited to a certain cohort range, they did not provide information about changes in the duration of grandparenthood.

Margolis (2016) was the first to present a systematic analysis of the possible changes in the length of the grandparent phase. Notably, using the Sullivan method, she combined cross-sectional survey data for Canada on the prevalence of grandparenthood status with data from period life tables to calculate the remaining years spent in grandparenthood. Her results demonstrated that from 1985 to 2011, grandparenthood was substantially delayed as a result of fertility postponement across two generations. However, it also turned out that those delays did not greatly affect the expected length of grandparenthood - about 24 years for women and 19 years for men - as declines in mortality rates meant that grandparents could expect to live longer. Thus, it appears that the combined effects of declines in fertility and in mortality have simply moved the grandparent phase to later years in life. Subsequent analyses have shown that this shift in the grandparent phase to older ages has not been accompanied by poor health, as the length of healthy grandparenthood has also been increasing (Margolis and Wright 2017). These findings suggest that the compression of morbidity has outpaced the postponement of grandparenthood (Margolis and Iciaszczyk 2015). The differences between the estimates of the length of grandparenthood in Margolis (2016) and in Leopold and Skopek (2015b) highlight some of the methodological challenges involved in the estimation of multigenerational indicators. The latter use a cohort approach and base their calculations on parents only (since, logically, only parents can become biological grandparents). As Margolis' period-based method takes into account all individuals (regardless of whether they are at risk of becoming grandparents), the use of this approach inflates the denominator and leads to lower duration estimates. Margolis and Verdery (2019) discuss this 'denominator problem' in more detail.

In a remarkable study of Finnish church records from the eighteenth to the twentieth century, Chapman et al. (2017) looked at how grandparenthood changed over a 170-year period. In their analysis, they were also able to distinguish between prospective (from the perspective of the grandparents) and retrospective (from the perspective of the grandchildren) views on grandparenthood. They found that over the observation period, the number of years of life grandparents and grandchildren shared had increased substantially. For example, the results indicated that from the pre-industrial to the post-World War II cohorts, the average number of years a child had at least one living grandmother went from around five to about 24; and the average number of years a grandmother had at least one living grandchild increased from approximately 12 to more than 25 . 
Two of the most recent studies on the demography of grandparenthood and multigenerational relations were again based on data from the US. Combining historical vital statistics with stable population kinship models (Goodman et al. 1974), Song and Mare (2019) analysed the impact of fertility and mortality trends on the mutual exposure of grandparents and grandchildren in the US from 1900 to 2010 . Their findings indicated that there had been a substantial enlargement of multigenerational exposure in the first half of the twentieth century in the US. For example, they found that the average number of years of life grandparents could expect to share with at least one grandchild rose from five in 1900 to about 35 in 1950 and later. They also showed that over the same period, the average number of years of life grandchildren could expect to share with at least one grandparent rose from 21 to 25 . These trends were mainly attributable to substantial declines in mortality rates. While Song and Mare's (2019) study relied on period data, Margolis and Verdery (2019) used for the first time a cohort perspective based on micro-simulations to examine racial differences in the changing demography of grandparenthood. While cohort measures on grandparenthood are generally limited to older cohorts, they can provide a more accurate picture than period approximations of how grandparenthood is unfolding over people's lives and successive cohorts. The results of these simulations suggested that the proportion of individuals with living grandparents had increased substantially as a result of mortality declines. However, the analysis also showed that the proportion of the population who never became a grandparent because of childlessness (their own or their offspring's) had increased as well. The findings indicated that among grandparents, the age at the transition to grandparenthood had been increasing, whereas the overall number of grandchildren had been sharply declining. Moreover, the study found that the length of the grandparenthood phase had increased substantially over the studied cohorts. While the results uncovered considerable heterogeneity by gender and race, they also showed that racial differences in grandparenthood experiences decreased substantially over the cohorts.

The available evidence suggests that there have been significant changes in the demographic trends in grandparenthood and in multigenerational relations. Changes in mortality and fertility are the two primary but opposing macro-demographic forces underpinning those changes. Thus, it is clear that declines in mortality have made the experience of grandparenthood more likely, and have increased the supply of living grandparents for younger generations. Research on the length of the grandparenthood phase indicates that as mortality declines have more than compensated for concurrent delays in fertility, grandparents and grandchildren are spending more years of life together than they did in the past. However, the literature review suggests this trend towards more years of shared life might have stalled.

\section{DEMOGRAPHIC TRENDS IN GRANDPARENTHOOD ACROSS EUROPE}

As the previous review has shown, we are just beginning to understand how the demography of intergenerational relations has been changing. This is especially the case for European societies, for which we have only fragmented evidence. Therefore, in the remainder of this chapter, I will present demographic approximations of how the experiences of grandparenthood might have changed in selected European countries. As there were no appropriate survey data for the task at hand, I derived multiple indicators on multigenerational relations based on demographic kinship theory (Caswell 2019; Goodman et al. 1974; Keyfitz and Caswell 
2005; Margolis and Verdery 2019; Song and Mare 2019): i.e., the supply of grandchildren, the timing of grandparenthood, the supply of grandparents, and the shared lifetime across generations. While I provide a short and non-technical description of the methods here, formal details can be found in the Appendix.

The proposed indicators cover both prospective (from the perspective of the grandparents) and retrospective (from the perspective of the grandchildren) viewpoints, which are needed to understand changes in the demography of multigenerational relations. The indicators were calculated using period data on female fertility and mortality schedules for nine countries, and for periods from the 1950s to the 2010s, which were retrieved from the Human Fertility and Human Mortality databases (HFD 2019; HMD 2019). It should be noted that due to the absence of male fertility data, all of the calculations refer to female lineages only (women bearing daughters who in turn bear daughters). Thus, in the analysis that follows, grandmotherhood is used as a proxy for grandparenthood. Furthermore, all of the numbers presented here are calculated based on general age-specific fertility rates, because parity-specific fertility data were not available for all countries and periods. ${ }^{1}$ Obviously, elaborations based on kinship models and period data are limited, and must be seen as approximations, and not as exact estimations. Nonetheless, in the absence of actual observational data, they provide a viable tool for exploring the question of how multigenerational relationships might have been changing over the past six decades in Europe. Moreover, such elaborations are helpful devices to determine empirically how changes in fertility and longevity have been affecting grandparent-grandchild relations in contemporary European societies.

\subsection{Supply of Granddaughters}

First, we inspect the trends in the supply of grandchildren. Figure 17.2 shows period approximations for the expected number of granddaughters of a hypothetical woman (who bears only female offspring, and who, in turn, bear only girls). ${ }^{2}$ For purposes of comparison, the figure also depicts the period fertility (total fertility rate). It should be noted that Germany is treated here and in the following analysis as two distinct regions: East and West. This is because Germany is known to have differences in fertility patterns related to its historic legacy of separation (Goldstein and Kreyenfeld 2011; Kreyenfeld 2003) that still resonate in contemporary patterns of grandparenthood in the two parts of the country (Leopold and Skopek 2015a).

The trends in period fertility (see also the chapter by Sobotka and Berghammer) are mirrored in the period 'supply' of grandchildren. As a consequence of declining birth rates, the 'birth rates' of grandchildren are declining as well. These changes appear to be most extreme for Ireland, where the average number of grandchildren each grandmother had declined sharply from about 16 (about 14 during her lifetime) in the mid-1960s to barely four in the 2010s. Based on 2014 fertility and mortality rates, women in France and in Ireland could expect to have the highest numbers of grandchildren (3.7 and 3.9, respectively), followed by women in Sweden (3.5) and England (3.3); while women in Spain and Italy ranked lowest in terms of 'grandchild supply', as they could expect to have fewer than two grandchildren (1.7 and 1.9, respectively). In sum, as the observed fertility declines imply that the number of grandchildren women are having is decreasing drastically, women are expected to experience a decline in multigenerational family ties over their lifetimes. 

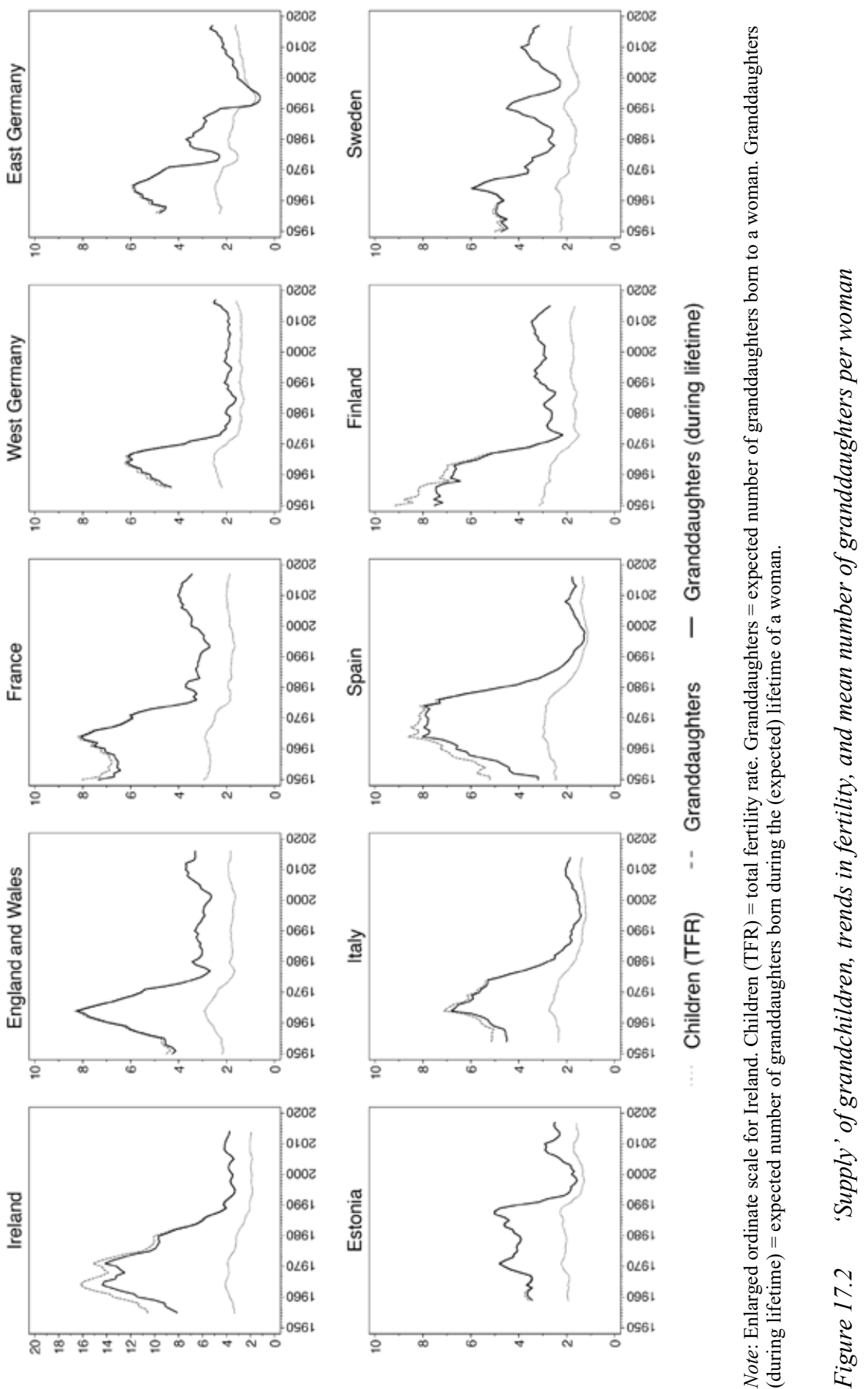

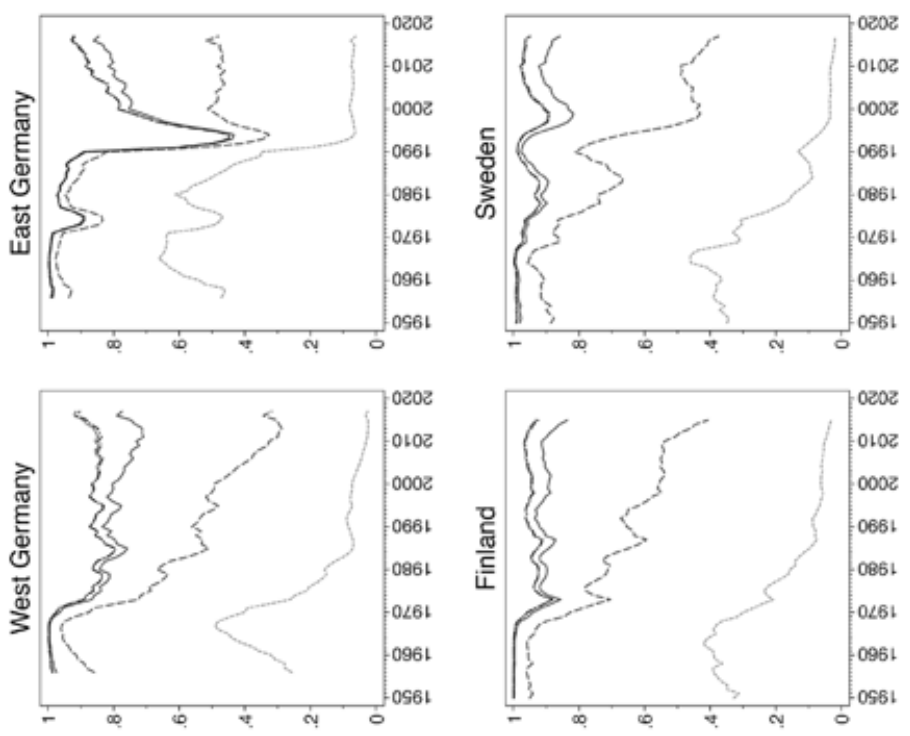

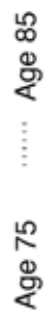
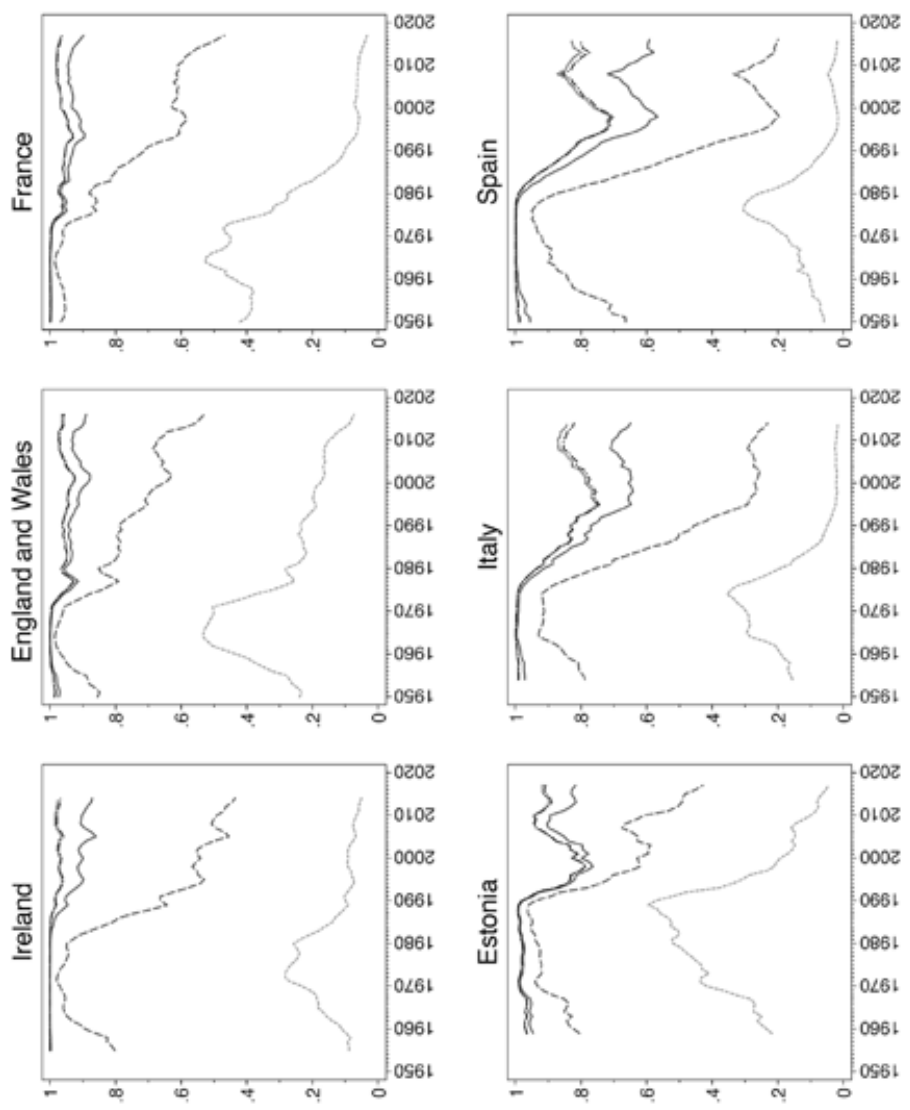


\subsection{Prevalence and Timing of Grandmotherhood}

How has the prevalence of grandparenthood changed over time? Figure 17.3 displays women's probabilities of being a grandmother (i.e., having at least one living granddaughter) by age and period. For all countries, the probabilities of grandmotherhood have decreased substantially, particularly at younger ages. The figure shows, for example, that while a woman's probability of having living grandchildren by the age of 55 was between 80 and 90 per cent in the 1960s and 1970s, this probability fell below 50 per cent - and even below 30 per cent for the Mediterranean countries - in the 2010s. Moreover, over all age groups, Spain and Italy stand out as having the lowest prevalence of grandmotherhood, while Ireland, England, and France have the highest prevalence. Summing up, we found that in successive periods, the prevalence of the grandmother role in the female population has been declining, particularly at younger ages.

The age at grandparenthood is another indicator for the demography of grandparenthood and of multigenerational relations. Figure 17.4 plots the median age at the transition to grandmotherhood (the age at which 50 per cent of women are expected to be a grandmother), as well as the average age at the birth of a granddaughter. While the age at childbirth declined from the early 1950s to the 1970s, it has been continuously rising since the 1980s in most European countries (Frejka and Sobotka 2008). Those delays in childbirth imply substantial delays in the age at the transition to grandparenthood. Figure 17.4 shows that the average age at the transition to grandmotherhood has been rising since the 1960s and the 1970s, except in the post-socialist countries (Estonia and East Germany), where the age did not start to increase until the late 1980s. Thus, over the last 40 years, the ages at which women experience the births of their grandchildren have risen substantially.

\subsection{Duration of Grandmotherhood}

While fertility predominantly determines the availability of living children and grandchildren, mortality predominantly determines the availability of living ancestors, such as parents and grandparents, as well as the number of years of life generations might share. Figure 17.5 summarises the changes in female longevity evaluated at three age points: at birth (life expectancy), at the average age when a daughter is born, and at the average age when a granddaughter is born. The numbers for the remaining years of life at the average age at the birth of a child and of a grandchild serve as indicators for the expected duration of motherhood and grandmotherhood. ${ }^{3}$ We first note the constant increase in life expectancy at birth from the 1950s (about 70 years) until today. Second, we observe that although this shift is less pronounced, the remaining years of life from the mean age at childbirth have also increased for all countries, which suggests that a woman alive today is likely to spend a larger share of her lifetime with her children than a woman in the past. Finally, we see that those upward trends do not quite hold for the remaining years of life at the birth of a woman's grandchild. Although a woman's remaining life expectancy at the birth of a grandchild was increasing up to the 1970s, in most countries (with the exception of Ireland), it has since remained unchanged or even declined. More precisely, those period approximations suggest that the expected lifetime 

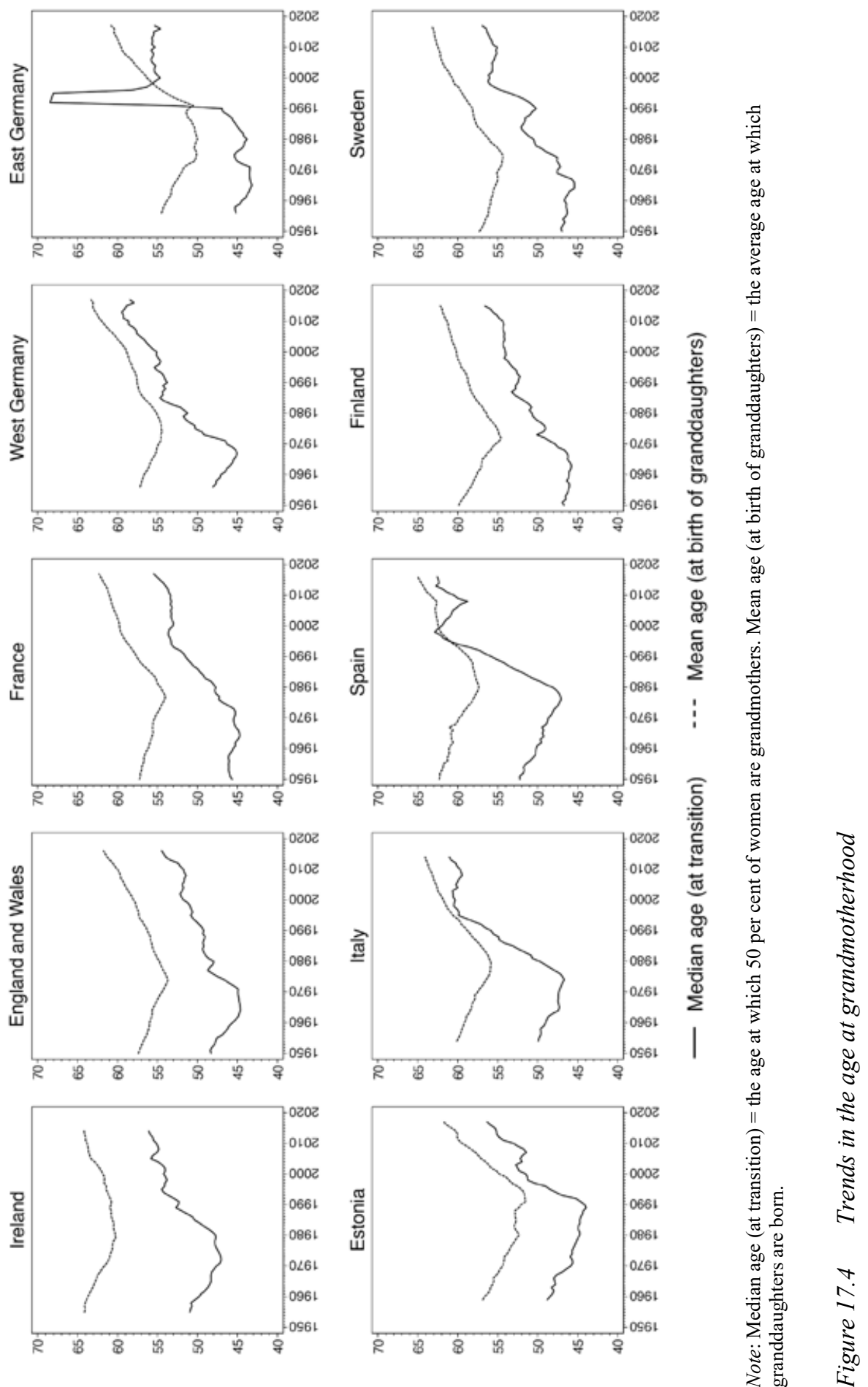
spent as a grandmother has been around 25 years (except in Ireland) for the last four decades. This pattern indicates that the positive effects of increasing longevity on the number of years of life grandmothers could share with their grandchildren might have been cancelled out by the opposite effects of reduced and delayed fertility.

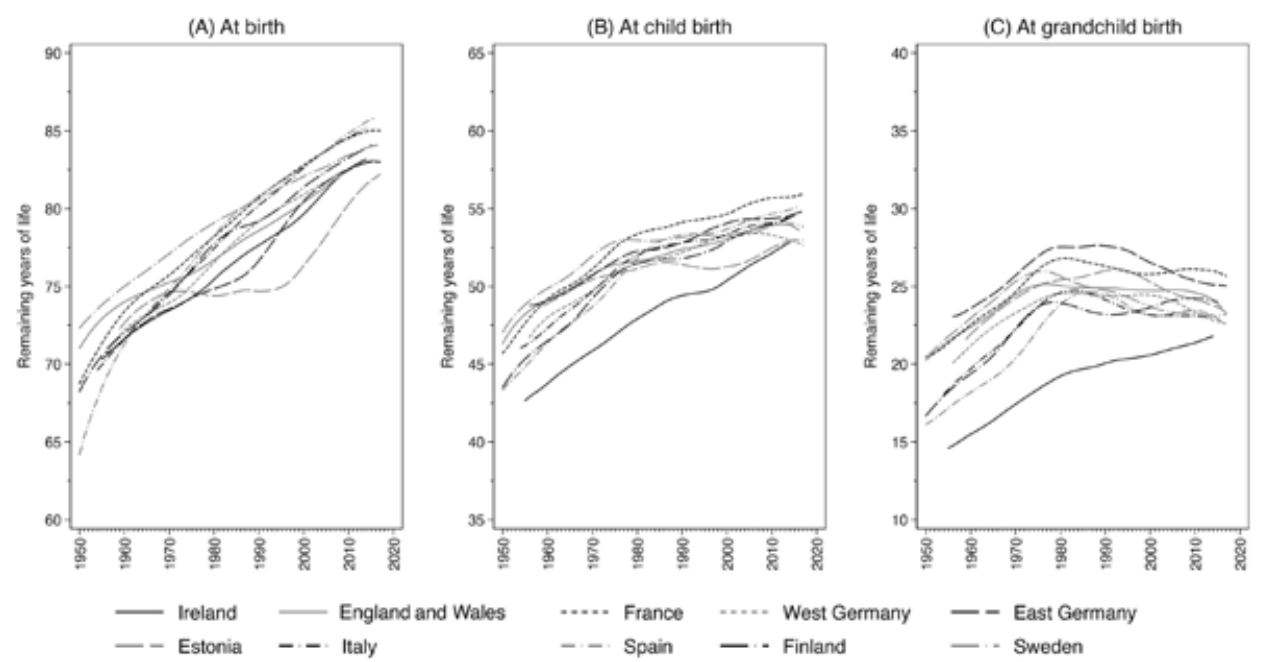

Note: Remaining years of life at birth = life expectancy at birth. Remaining years at child birth (average age at birth of children) $=$ duration of motherhood. Remaining years at grandchild birth (average age at birth of granddaughters) $=$ duration of grandmotherhood. Time series smoothed.

\section{Figure 17.5 Remaining years of life at birth, childbirth, and grandchild birth}

When we look at these questions from the perspective of the grandchildren, we can ask what the probability is of having living grandparents at various ages. We would expect to find that reduced mortality has increased the 'supply' of living grandparents for the younger generations. Figure 17.6 plots a woman's (and a girl's) probability of having a living (maternal) grandmother at different ages. We can see that the probability of having a living grandmother increased from the 1950 s to the 1970 s, but that for the later periods, this trend seems to have stalled or even reversed for most countries. These findings indicate, for example, that in Italy, the share of young women who had a living grandmother at age 25 was slightly higher than 30 per cent, and that this share had increased to almost 55 per cent by 1980 , but had declined to less than 50 per cent by 2015 . An exception to this general pattern was found for Ireland, where the age-specific probabilities of having a living grandmother have increased steadily. It appears that the rise in the average age at childbirth and the corresponding delay in grandparenthood has counteracted the increase in longevity in most countries. In sum, we can state that after some initial increases, the supply of grandparents has not changed for minor children since the 1970s, while the chances of having living grandparents may have even declined for adults. 

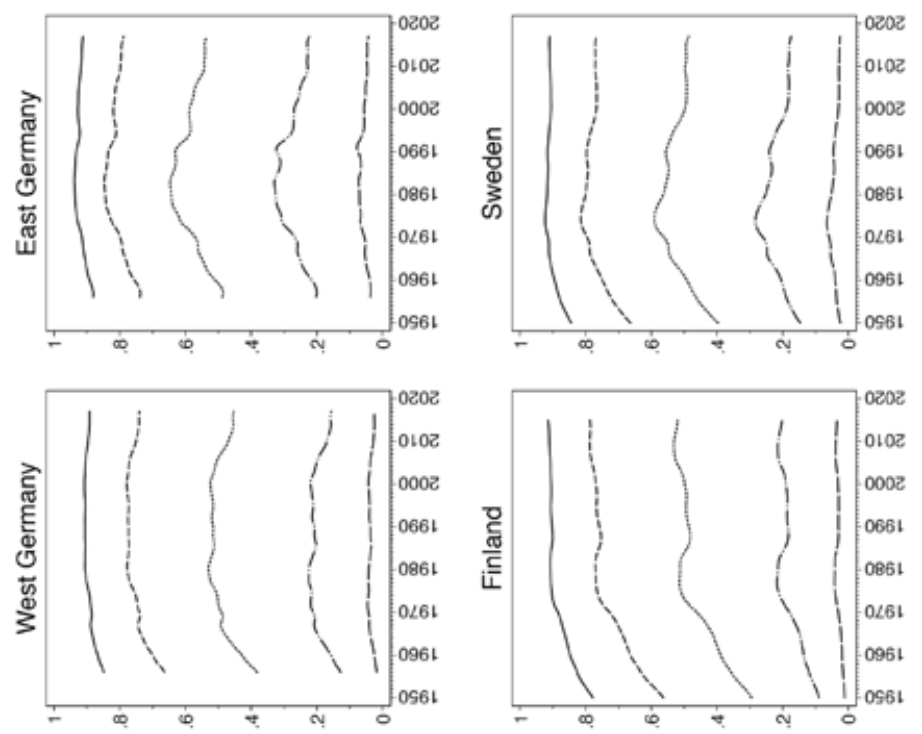

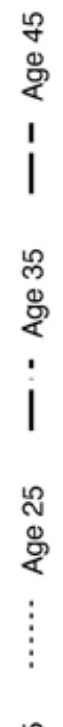
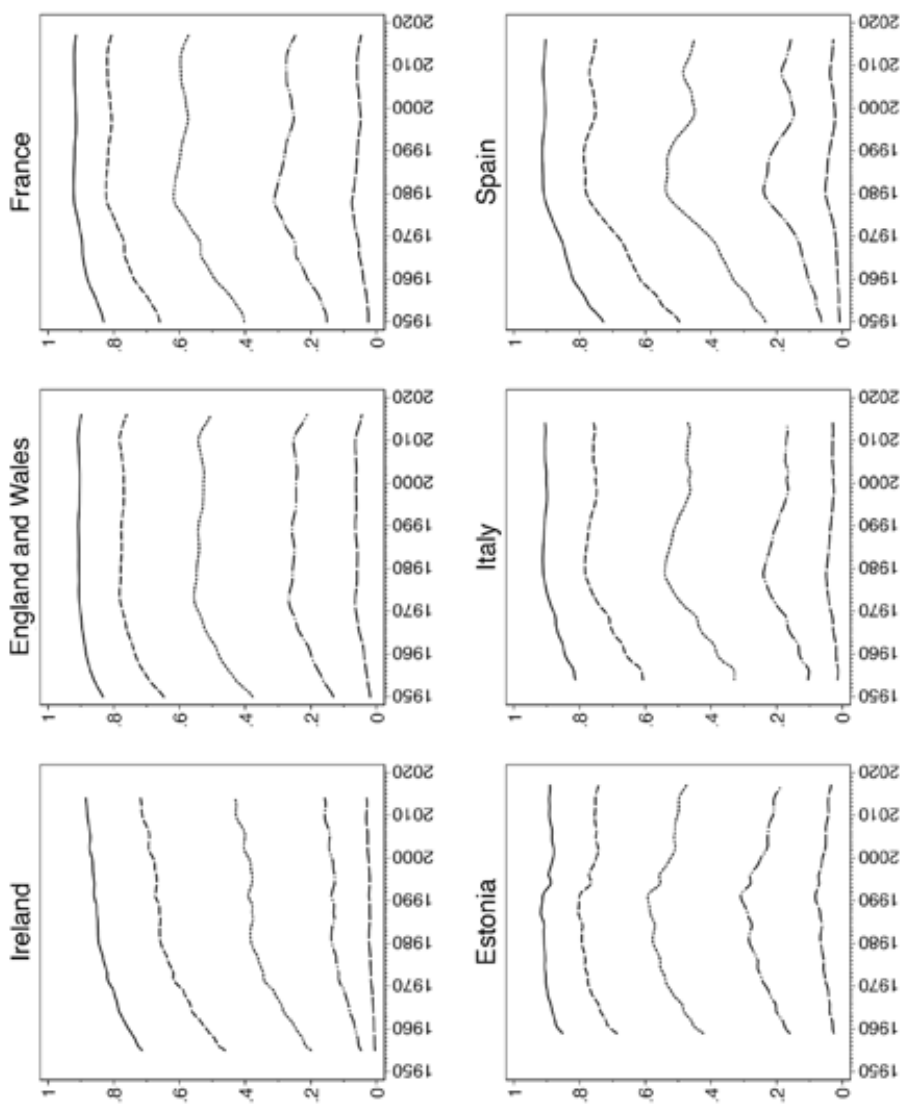

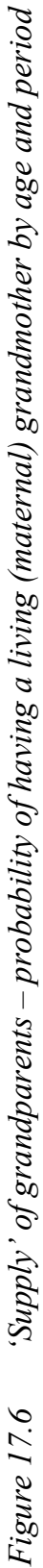




\section{DISCUSSION AND CONCLUSION}

Multigenerational relations are attracting increasing scholarly attention, as the surge in the number of studies on grandparenthood indicates. In this chapter, I highlighted the conceptual and the methodological progress that has been made in the study of grandparenthood over the last decades. There have been advancements in methods, such as employing survival analysis, formal demography, and micro-simulation. In addition, the availability of survey data that include information on the 'timing' of grandparenthood has been increasing. Nonetheless, apart from cursory references to changes in grandparenthood, studies that have attempted to investigate the changing demographic fabric of grandparenthood and multigenerational relations are still rare. After reviewing the scant and mainly North American-centric literature, I discussed in this chapter the shortage of research on the changing demography of grandparenthood in European societies.

Against this backdrop, I used demographic kinship models to construct a series of multigenerational period indicators that allowed me to assess trends in the demography of grandparenthood over the past 60 years in nine European countries. The findings revealed that demographic changes in multigenerational relations have been more complex than was previously assumed. The trends for European countries are frequently non-linear, and often differ across countries. Nonetheless, three general patterns emerged. First, the 'supply' of grandchildren - and, therefore, the numbers of multigenerational family ties that women (who were the focus of the analysis) experience over their lifetimes - have decreased substantially over time. Second, the age at which the typical woman experiences grandparenthood has increased steadily, and the population prevalence of grandparenthood has declined accordingly for all age groups. Third, 'multigenerational lifetime exposure' - approximated here by the expected duration of grandparenthood and the age-specific probability of having living grandparents - does not seem to follow a consistent trend. Whereas reduced mortality has tended to increase the shared years of life of grandchildren and grandparents, pronounced delays in the age at the transition to grandparenthood and reductions in the number of grandchildren seem to have offset these positive longevity effects to a considerable extent. The demographic approximations conducted in this chapter suggest that although the years of life shared by grandparents and their grandchildren had initially been rising starting in the 1950s, the level of shared lifetime remained largely unchanged, and has in some cases even declined over the past four decades. However, it is possible that multigenerational exposure might start increasing again in the future if longevity continues to increase and the trends towards (lowest-)low fertility are reversed (Goldstein et al. 2009; Kontis et al. 2017). Nonetheless, despite the stalled gains in shared lifetime between the generations, the decline in the 'supply' of grandchildren might have altered many aspects of the grandparent-grandchild relationship. If grandparents have fewer grandchildren, they may develop stronger emotional bonds with particular grandchildren. In addition, the monetary and non-monetary resources of the grandparents will be shared by fewer children.

\section{NOTES}

1. More refined analyses incorporating parity-specific data would be able to approximate levels of childlessness and, consequentially, grandchildlessness.

2. Note that the period indicators may be affected by tempo effects (see Sobotka and Berghammer in this volume). 
3. It is important to keep in mind that as the analyses presented here cannot distinguish parities (the order of childbirths), they have to incorporate the age at any (grand)child birth rather than the age at the first (grand)child birth. As a consequence, these approximations necessarily understate the actual duration of motherhood and grandmotherhood. Nonetheless, these numbers can be used to explore trend patterns in the respective durations.

\section{REFERENCES}

Arpino, B. and V. Bordone (2014), 'Does grandparenting pay off? The effect of child care on grandparents' cognitive functioning', Journal of Marriage and Family, 76, 337-51. doi:10.1111/jomf.12096.

Arpino, B., J. Gumà, and A. Julià (2017), 'The demography of grandparenthood: The role of family histories (No. 50)', RECSM Working Paper, Barcelona, Spain. doi:10230/30802.

Arpino, B., V. Bordone, and N. Balbo (2018), 'Grandparenting, education and subjective well-being of older europeans', European Journal of Ageing, 15 (3), 1-13. doi:10.1007/s10433-018-0467-2.

Bavel, J. Van and T. De Winter (2013), 'Becoming a grandparent and early retirement in Europe', European Sociological Review, 29 (6), 1295-308. doi:10.1093/esr/jct005.

Bengtson, V.L. (2001), 'Beyond the nuclear family: The increasing importance of multigenerational bonds', Journal of Marriage and Family, 63, 1-16. doi:10.1111/j.1741-3737.2001.00001.x.

Bol, T. and M. Kalmijn (2016), 'Grandparents' resources and grandchildren's schooling: Does grandparental involvement moderate the grandparent effect?', Social Science Research, 55, 155-70. doi:10 .1016/j.ssresearch.2015.09.011.

Burn, K. and C. Szoeke (2015), 'Grandparenting predicts late-life cognition: Results from the women's healthy ageing project', Maturitas, 81 (2), 317-22. doi:10.1016/j.maturitas.2015.03.013.

Caswell, H. (2019), 'The formal demography of kinship: A matrix formulation', Demographic Research, 41, 679-712. doi:10.4054/demres.2019.41.24.

Chan, T.W. and V. Boliver (2013), 'The grandparents effect in social mobility: Evidence from British birth cohort studies', American Sociological Review, 78 (4), 662-78. doi:10.1177/0003122413489130.

Chapman, S.N., M. Lahdenperä, J.E. Pettay, and V. Lummaa (2017), 'Changes in length of grandparenthood in Finland 1790-1959', Finnish Yearbook of Population Research, 52, 3-13. doi:10.23979/ fypr.65346.

Cherlin, A. and F.F. Furstenberg (1986), 'Grandparents and family crisis', Generations: Journal of the American Society on Aging, 10 (4), 26-8.

Condon, J., M. Luszcz, and I. McKee (2018), 'The transition to grandparenthood: A prospective study of mental health implications', Ageing and Mental Health, 22 (3), 336-43. doi:10.1080/13607863.2016 .1248897.

Di Gessa, G., K. Glaser, and A. Tinker (2016), 'The health impact of intensive and nonintensive grandchild care in europe: New evidence from SHARE', Journal of Gerontology-Series B Social Sciences, 71 (5), 867-79. doi:10.1093/geronb/gbv055.

Dykstra, P.A. and A.E. Komter (2006), 'Structural characteristics of Dutch kin networks', in P.A. Dykstra, M. Kalmijn, T.C.M. Knijn, A.E. Komter, A.C. Liefbroer, and C.H. Mulder (eds), Family Solidarity in the Netherlands, Amsterdam: Dutch University Press, pp. 21-42.

Frejka, T. and T. Sobotka (2008), 'Overview chapter 1: Fertility in Europe: Diverse, delayed and below replacement', Demographic Research, 19, 15-46. doi:10.4054/DemRes.2008.19.3.

Goldstein, J.R. and M. Kreyenfeld (2011), 'Has East Germany overtaken West Germany? Recent trends in order-specific fertility', Population and Development Review, 37 (3), 453-72. doi:10.1111/ j.1728-4457.2011.00430.x.

Goldstein, J.R., T. Sobotka, and A. Jasilioniene (2009), 'The end of "lowest-low” fertility ?', Population and Development Review, 35 (4), 663-99. doi:10.1111/j.1728-4457.2009.00304.x.

Goodman, L.A., N. Keyfitz, and T.W. Pullum (1974), 'Family formation and the frequency of various kinship relationships', Theoretical Population Biology, 5 (1), 1-27. doi:10.1016/ 0040-5809(74)90049-5.

Hagestad, G.O. (1988), 'Demographic change and the life course: Some emerging trends in the family realm', Family Relations, 37 (4), 405-10. doi:10.2307/584111. 
Hagestad, G.O. and L.M. Burton (1986), 'Grandparenthood, life context, and family development', American Behavioral Scientist, 29 (4), 471-84. doi:10.1177/000276486029004008.

Hagestad, G.O.and M.E. Lang (1986), 'The transition to grandparenthood: Unexplored issues', Journal of Family Issues, 7 (2), 115-30. doi:10.1177/019251386007002001.

Hank, K. and I. Buber (2009), 'Grandparents caring for their grandchildren: Findings from the 2004 survey of health, ageing, and retirement in Europe', Journal of Family Issues, 30 (1), 53-73. doi:10 $.1177 / 0192513$ X08322627.

Hank, K., G. Cavrini, G. Di Gessa, and C. Tomassini (2018), 'What do we know about grandparents? Insights from current quantitative data and identification of future data needs', European Journal of Ageing, 15 (3), 225-35. doi:10.1007/s10433-018-0468-1.

Herlofson, K. and G.O. Hagestad (2011), 'Challenges in moving from macro to micro: Population and family structures in ageing societies', Demographic Research, 25, 337-70. doi:10.4054/DemRes .2011.25.10.

Hertel, F.R. and O. Groh-Samberg (2014), 'Class mobility across three generations in the US and Germany', Research in Social Stratification and Mobility, 35, 35-52. doi:10.1016/j.rssm.2013.09.007.

HFD (2019), Human Fertility Database, Max Planck Institute for Demographic Research (Germany) and Vienna Institute of Demography (Austria), accessed 1 November 2019 at www.humanfertility.org.

HMD (2019), Human Mortality Database, University of California, Berkeley (USA), and Max Planck Institute for Demographic Research (Germany), accessed 1 November 2019 at www.mortality.org.

Hughes, M.E., L.J. Waite, T.A. Lapierre, and Y. Luo (2007), 'All in the family: The impact of caring for grandchildren on grandparents' health', Journal of Gerontology - Series B Social Sciences, 62 (2), 108-19. doi:10.1093/geronb/62.2.S108.

Jappens, M. and J. Van Bavel (2019), 'Relationships with grandparents and grandchildren's well-being after parental divorce', European Sociological Review, 35 (6), 1-15. doi:10.1093/esr/jcz033.

Kemp, C.L. (2003), 'The social and demographic contours of contemporary grandparenthood: Mapping patterns in Canada and the United States', Journal of Comparative Family Studies, 34, pp. 187-212. doi:10.3138/jcfs.34.2.187.

Keyfitz, N. and H. Caswell (2005), Applied Mathematical Demography, 3rd edition, New York: John Wiley and Sons. doi:10.2307/3314924.

Kontis, V., J.E. Bennett, C.D. Mathers, G. Li, K. Foreman, and M. Ezzati (2017), 'Future life expectancy in 35 industrialised countries: Projections with a Bayesian model ensemble', The Lancet, 389 (10076), 1323-35. doi:10.1016/S0140-6736(16)32381-9.

Kreyenfeld, M. (2003), 'Crisis or adaptation - reconsidered: A comparison of East and West German fertility patterns in the first six years after the Wende', European Journal of Population, 19, 303-29. doi:10.1023/A:1024992712815.

Leopold, T. and J. Skopek (2014), 'Gender and the division of labor in older couples: How European grandparents share market work and childcare', Social Forces, 93 (1), 63-91. doi:10.1093/sf/sou061.

Leopold, T. and J. Skopek (2015a), 'The delay of grandparenthood: A cohort comparison in East and West Germany', Journal of Marriage and Family, 77 (2), 441-60. doi:10.1111/jomf.12169.

Leopold, T. and J. Skopek (2015b), 'The demography of grandparenthood: An international profile', Social Forces, 94 (2), 801-32. doi:10.1093/sf/sov066.

Lesthaeghe, R. (2010), 'The unfolding story of the second demographic transition', Population and Development Review, 36 (2), 211-51. doi:10.1111/j.1728-4457.2010.00328.x.

Luo, Y., T.A. LaPierre, M.E. Hughes, and L.J. Waite (2012), 'Grandparents providing care to grandchildren: A population-based study of continuity and change', Journal of Family Issues, 33 (9), 1143-67. doi:10.1177/0192513X12438685.

Lye, D.N. (1996), 'Adult child-parent relationships', Annual Review of Sociology, 22, 79-102. doi:10 $.4324 / 9781351156882-9$.

Margolis, R. (2016), 'The changing demography of grandparenthood', Journal of Marriage and Family, 78, 610-22. doi:10.1111/jomf.12286.

Margolis, R. and N. Iciaszczyk (2015), 'The changing health of Canadian grandparents', Canadian Studies in Population, 42 (3-4), 63-76. doi:10.25336/P6J88R.

Margolis, R. and A.M. Verdery (2019), 'A cohort perspective on the demography of grandparenthood: Past, present, and future changes in race and sex disparities in the united states', Demography, 56 (4), 1495-518. doi:10.1007/s13524-019-00795-1. 
Margolis, R. and L. Wright (2017), 'Healthy grandparenthood: How long is it, and how has it changed?', Demography, 54, 2073-99. doi:10.1007/s13524-017-0620-0.

Minkler, M. and E. Fuller-Thomson (1999), 'The health of grandparents raising grandchildren', American Journal of Public Health, 89 (9), 1384-9. doi:10.3928/00989134-20140219-01.

Modin, B. and J. Fritzell (2009), 'The long arm of the family: Are parental and grandparental earnings related to young men's body mass index and cognitive ability?', International Journal of Epidemiology, 38 (3), 733-44. doi:10.1093/ije/dyp001.

Modin, B., R. Erikson, and D. Vagero (2012), 'Intergenerational continuity in school performance: Do grandparents matter?', European Sociological Review, 29 (4), 858-70. doi:10.1093/esr/jcs064.

Musil, C.M., N.L. Gordon, C.B. Warner, J.A. Zauszniewski, T. Standing, and M. Wykle (2011), 'Grandmothers and caregiving to grandchildren: Continuity, change, and outcomes over 24 months', The Gerontologist, 51 (1), 86-100. doi:10.1093/geront/gnq061.

Presser, H.B. (1989), 'Some economic complexities of child care provided by grandmothers', Journal of Marriage and Family, 51 (3), 581-91. doi:10.2307/352158.

Silverstein, M. and J.D. Long (1998), 'Trajectories of grandparents' perceived solidarity with adult grandchildren: A growth curve analysis over 23 years', Journal of Marriage and the Family, 60 (4), 912-23. doi:10.2307/353634.

Skopek, J. and T. Leopold (2017), 'Who becomes a grandparent - and when? Educational differences in the chances and timing of grandparenthood', Demographic Research, 37, 917-28. doi:10.4054/ DemRes.2017.37.29.

Song, X. and R.D. Mare (2019), 'Shared lifetimes, multigenerational exposure, and educational mobility', Demography, 56, 891-916. doi:10.1007/s13524-019-00772-8.

Spitze, G. and R.A. Ward (1998), 'Gender variations', in M.E. Szinovacz (ed.), Handbook on Grandparenthood, Westport, CT: Greenwood Press, pp. 113-27.

Szinovacz, M.E. (1998a), 'Grandparent research: Past, present, and future', in M.E. Szinovacz (ed.), Handbook on Grandparenthood, Westport, CT: Greenwood Press, pp. 1-20.

Szinovacz, M.E. (1998b), 'Grandparents today: A demographic profile', The Gerontologist, 38 (1), 37-52. doi:10.1093/geront/38.1.37.

Szinovacz, M.E. and A. Davey (2005), 'Predictors of perceptions of involuntary retirement', The Gerontologist, 45 (1), 36-47.

Thompson, P. (1999), 'The role of grandparents when parents part or die: Some reflections on the mythical decline of the extended family', Ageing and Society, 19 (4), 471-503. doi:10.1017/ S0144686X99007461.

Treas, J. and V.L. Bengtson (1982), 'The demography of mid- and late-life transitions', Annals of the American Academy of Political and Social Science, 464, 11-21. doi:10.1177/0002716282464001002.

Uhlenberg, P. (1980), 'Death and the family', Journal of Family History, 5 (3), 313-20. doi:10.1177/ 036319908000500304.

Uhlenberg, P. (1996), 'Mortality decline in the twentieth century and supply of kin over the life course', The Gerontologist, 36 (5), 681-5. doi:10.1093/geront/36.5.681.

Uhlenberg, P. and J.B. Kirby (1998), 'Grandparenthood over time: Historical and demographic trends', in M.E. Szinovacz (ed.), Handbook on Grandparenthood, Westport, CT: Greenwood Press, pp. 23-39.

Wightman, P. and S. Danziger (2014), 'Multi-generational income disadvantage and the educational attainment of young adults', Research in Social Stratification and Mobility, 35, 53-69. doi:10.1016/ j.rssm.2013.09.004.

Zeng, Z. and Y. Xie (2014), 'The effects of grandparents on children's schooling: Evidence from rural China', Demography, 51 (2), 599-617. doi:10.1007/s13524-013-0275-4. 


\section{APPENDIX}

All indicators are developed based on demographic theory using the kinship model proposed by Goodman et al. (1974) as a point of departure (see also Keyfitz and Caswell 2005, p. 381; and for recent extensions, Song and Mare 2019). The 'GKP' model provides a systematic and formal framework for the demographic analysis of the frequency of various kinds of kin - such as the number of siblings, the number of grandchildren, or the probability of having living grandparents - based on specified birth and death rates. Based on this model, the expected number of living granddaughters (here, daughters of daughters) for a woman of age $a$ is defined as

$$
D_{2}(a)=\int_{\alpha}^{a}\left[\int_{\alpha}^{a-x} l(y) m(y) l(a-x-y) d y\right] m(x) d x
$$

with the minimum childbearing age $\alpha$, woman's fertility function $m(x)$, daughter's fertility function $m(y)$, daughter's survival up to childbearing $l(y)$, and granddaughters' survival up to the time the woman is of age $l(a-x-y)$. Note that $m(x) d x$ is the number of daughters a woman is expected to bear over interval $d x$ and $l(x)$ is a woman's probability of surviving up to age $x$. For my analysis, I use a slight modification of (17A.1) to measure the number of grandchildren a woman is expected to have during her expected lifetime. This measure integrates over a woman's and her (surviving) daughters' fertility function up to the woman's life expectancy at birth $e_{0}$, and does not depend on the granddaughters' survival:

$$
N_{2}=\int_{\alpha}^{e_{0}}\left[\int_{\alpha}^{e_{0}-x} l(y) m(y) d y\right] m(x) d x
$$

Modelling a woman's number of grandchildren by a Poisson distribution (see Song and Mare 2019), the probability of being a grandmother (i.e., the probability of having at least one living granddaughter) at age $a$ can be written as the inverted probability of having no granddaughters

$$
P_{2}(a)=1-e^{-D_{2}(a)}
$$

In addition, I evaluate the mean age at the birth of granddaughters. The mean age of the childbearing function $m(x)$, the expected age of a woman at childbirth, is (see Keyfitz and Caswell 2005, pp. 386-7)

$$
A_{1}=\int_{\alpha}^{\beta} x m(x) d x\left[\int_{\alpha}^{\beta} m(x) d x\right]^{-1}
$$

the $\alpha$ being the earliest and $\beta$ being the latest age at childbirth. Correspondingly, the mean age at the birth of granddaughters for a woman at age $2 \beta$ (i.e., when her youngest daughters had given birth to their youngest daughters) is

$$
\begin{aligned}
& A_{2}=\left[\int_{\alpha}^{2 \beta}\left[\int_{\alpha}^{2 \beta-x} l(y) m(y) d y\right] m(x) x d x\right] \\
& {\left[\left[\int_{\alpha}^{2 \beta}\left[\int_{\alpha}^{2 \beta-x} l(y) m(y) d y\right] m(x) d x\right]\right]^{-1}}
\end{aligned}
$$


To have a better indicator for the timing of the transition to grandparenthood in the population of women, we can calculate the median age at which a woman is expected to become a grandmother. Reusing the Poisson assumption from (17A.3), we define the median age as the age $A_{2}^{M}$ at which the probability of being a grandmother (of living or deceased grandchildren) equals 0.5 :

$$
1-\exp \left\{-\int_{\alpha}^{A_{2}^{M}}\left[\int_{\alpha}^{A_{2}^{M}-x} l(y) m(y) d y\right] m(x) d x\right\}=0.5
$$

To measure the supply of grandparents, the probability of having grandparents at different ages is evaluated. The probability of a girl or a woman having a living mother at age $a$ is defined as (see Keyfitz and Caswell 2005, pp. 373-5)

$$
M_{1}(a)=\int_{\alpha}^{\beta} \frac{l(x+a)}{l(x)} e^{-r x} l(x) m(x) d x
$$

with $r$ being the intrinsic rate of population growth in a stable population (featuring fertility regime $m(x)$ and mortality regime $l(x)$ ). Correspondingly, the probability of having a living (maternal) grandmother at some age $a$ is (Keyfitz and Caswell 2005, p. 375)

$$
M_{2}(a)=\int_{\alpha}^{\beta} M_{1}(x+a) e^{-r x} l(x) m(x) d x
$$

Using the equations above, I calculated multigenerational indicators for grandparentgrandchild relations based on historical fertility and mortality data in Europe. The period data on fertility and mortality came from the Human Fertility Database (HFD 2019) and the Human Mortality Database (HMD 2019). To keep the number of countries analysed manageable, but to nonetheless ensure adequate coverage of the variety of European welfare states, I decided to include the following 10 analytical cases (covering nine countries) for which sufficient data were available: England (and Wales) and Ireland (the liberal cluster), France and West Germany (central/continental), Estonia and East Germany (post-socialist), Italy and Spain (Mediterranean), and Finland and Sweden (Nordic regimes). Note that Germany must be treated as two distinct cases, as it is well known that the historical legacy of the separation of the country into East and West Germany is associated with differences in fertility.

As the Human Fertility Database provides only female fertility data, the analysis had to be restricted to female family lineages only. Note also that $D_{2}(a)$ (17A.1) depicts only the expected number of living granddaughters in the maternal lineage. However, to calculate the overall number of living grandchildren, we would need to combine female with male data on fertility and mortality. If males equalled the fertility and mortality schedules of females, the overall number of living grandchildren would simply be $D_{2}(a) \times 4$. Alternatively, $D_{2}(a) \times 4$ would be the expected number of grandchildren for a hypothetical woman who bears only daughters, and her daughters have only daughters too. It is this number that we will be evaluating in the results part. Note that the approximation made by those demographic models builds upon general age-specific fertility rates. While more refined models could incorporate parity-specific fertility data, such data are not available for all of the countries and periods under study. 
The equations presented above define integrals and age-continuous functions for fertility and survival data. In practice, vital data, such as age-specific fertility (calculated from birth rates) and survival (calculated from death rates) data, are provided in discrete (annual) form. Therefore, the integral must be approximated numerically. Since numerical integration over nested integrals for 10 cases, each with about 60 periods, is computationally unreasonably expensive, I used Caswell's more efficient matrix method (Caswell 2019; Keyfitz and Caswell 2005), and a related MATLAB program that was recently provided by Caswell (2019). 